Proceedings of the Symposium on X-ray Methods in Corrosion and Interfacial Electrochemistry, Eds: A. J. Davenport and J. G. Gordon, PV 92-1, The Electrochemical Society, Fall Meeting, Phoenix, October 13-18 (1991).

BNL-47114

\title{
IN SITU XANES DETECTION OF Cr(VI) IN THE PASSIVE FILM ON Fe-26Cr
}

\author{
J.A. Bardweil ${ }^{\dagger}$, A.J. Davenport ${ }^{\ddagger}$, H.S. Isaacs ${ }^{\ddagger}$, G.I. Sproule ${ }^{\dagger}$, B. MacDougall ${ }^{\dagger}$ \\ and M.J. Graham ${ }^{\dagger}$ \\ Institute for Microstructural Sciences, National Research Council, \\ Ottawa, Canada, K1A OR9, \\ and \\ ‡Department of Applied Science, Brookhaven National \\ Laboratory, Upton, New York 11973.
}

DE92 010050

The passive film on sputter deposited thin film $\mathrm{Fe}-26 \mathrm{Cr}$ electrodes has been examined using the technique of in situ $\mathrm{X}$-ray absorption near edge spectroscopy (XANES). During the $X$-ray spectroscopic measurements, the sample was maintained under electrochemical control in the pH 8.4 borate buffer electrolyte. The appearance of the distinctive CrVI) XANES pre-edge peak can be correlated with the transpassive wave in the cyclic voltammogram, an: its disafpearance with the corresponding reduction wave. The formation and reduction of Cr(VI) was reversible, and only small amounts were detected in the film. $\mathrm{Cr}(\mathrm{VI})$ in the passive film is not indefinitely stable, and it is completely absent after long periods of air exposure.

\section{INTRODUCTION}

The presence of $\mathrm{Cr}$ (VI) in the passive film on $\mathrm{Fe}-\mathrm{Cr}$ and other stainless steel alloys has been postulated for many years. The transpassive peak observed on anodic polarization is often assumed to be due to the oxidation of $\mathrm{Cr}$ (III) to $\mathrm{Cr}$ (VI) because of the anodic potential at which the peak first appears. The presence of $\mathrm{Cr}(\mathrm{VI})$ in solution at these potentials has been confirmed (1), however, convincing evidence for the presence of $\mathrm{Cr}(\mathrm{VI})$ in the oxide film, from either in sith or ex sim techniques has been elusive. Clayton and $\mathrm{Lu}(2)$ have deconvoluted $x$-ray photoelectron spectra (XPS) to give a peak corresponding to Cr(VI), however, the presence of this peak is obscured by other overlapping peaks, and it is somewhat difficult tc quantify. In addition, the peak disappears with time of exposure to the x-ray raciation, and thus Cr(VI) is thought to be subject to photoreduction (3). Hara and Sugimoto (4), using modulation spectroscopy, an in situ optical technique, identified in optical peak at $3.7 \mathrm{eV}$ which they tentatively attributed to $\mathrm{Cr}(\mathrm{VI})$. This peak increased with the $\mathrm{Cr}$ concentration of the $\mathrm{Fe}-\mathrm{Cr}$ alloys, however, it could also be attributed to $\mathrm{Fe}(\mathrm{II})$, making an unequivocal assignment impossible. In recent electrochemical studies (5), it has been shown that the characteristics of $\mathrm{Cr}(\mathrm{VI})$, which are present for samples passivated above a certain potential, are eliminated after a brief ( $15 \mathrm{~min}$.) air exposure of the passivated sample. This suggests that $\mathrm{Cr}(\mathrm{VI})$ in the passive film on $\mathrm{Fe}-\mathrm{Cr}$ alloys is not stable, and thus evidence for $\mathrm{Cr}(\mathrm{VI})$ should be sought using in situ techniques.

Long et al (6) showed that thermal oxide films (formed at $600^{\circ} \mathrm{C}$ ) on $\mathrm{Fe}-25 \mathrm{Cr}$ contained Cr(VI) from ex situ XANES analysis. Davenport et al (7) have recently shown that anodic oxide films on Al-Cr alloys contained $\mathrm{Cr}(\mathrm{VI})$ by using XANES. In this case, 
the anodic films were examined in situ and under electrochemical control. In the present work, the in situ XANES technique has been used to demonstrate that Cr(VI) is present in the passive film on $\mathrm{Fe}-26 \mathrm{Cr}$ alloy at potentials in the transpassive region. The stability of $\mathrm{Cr}(\mathrm{VI})$ with respect to air exposure was also investigated.

\section{EXPERIMENTAL}

The experimental setup for the in situ XANES measurements has been described previously (7). Potentials are quoted with respect to a saturated mercurous sulfate reference electrode (MSE) and are accurate to $\pm 5 \mathrm{mV}$. The electrolyte was $\mathrm{pH} 8.4$ borate buffer, deaerated with nitrogen bubbling. Bubbling was continued during the course of a XANES experiment to ensure that any dissolved reaction products (such as $\mathrm{Cr}^{6+}$ ) were removed from the vicinity of the electrode and thus would not contribute to the observed spectra. The electrochemical cell design $(7,8)$ allows for potential control of the working electrode, which consisted of a $6 \mu \mathrm{m}$ Mylar film on which two metallic layers were sputtered The lower layer consisted of 10-20 nm of Ta metal (used to provide good electrical conductivity) and the upper layer of $4-6 \mathrm{~nm}$ of Fe-26Cr. The samples were prepared using an Ion Tech sputter coater equipped with a getter pump (SAES), in order to reduce the oxygen contamination of the metal layers. Ar was used as the sputtering gas. The sputter rate was calibrated by sputtering thicker films and measuring the thickness with a Sloan Dektak II step gauge. Auger depth profiles confirmed that the film thickness was proportional to sputter time. The bulk $\mathrm{Fe}-26 \mathrm{Cr}$ alloy was prepared as discussed previously (5).

\section{RESUL,TS AND DISCUSSION}

Auger analysis of the sputtered films on Mylar substrates revealed that the Ta and $\mathrm{Fe}-26 \mathrm{Cr}$ layers contained significant amounts of $\mathrm{C}$, present as carbide. Despite numerous efforts to reduce the $C$ level in the metallic layers, it remained at approximately the same atomic concentration as the $\mathrm{Cr}$. Samples sputtered onto Al foil or Si wafers under the same conditions contained much lower levels of $\mathrm{C}$, but the thin film $\mathrm{Al}$ substrates could not be used for XANES analysis because the signal was destroyed by Bragg scattering from the substrate. Samples spurtered onto Kapton, another X-ray transparent polymer, showed similar levels of $\mathrm{C}$ contamination. Thus, it appears that Mylar or other polymers are sources for $\mathrm{C}$ contamination. Mylar samples were used in this work, and so the $\mathrm{Fe}-\mathrm{Cr}$ alloy used in this study is rather heavily contaminated with $C$. Only the surface of the sample showed significant $\mathrm{O}$, resulting from the air-formed film. No $\mathrm{C}$ was present in the oxide layer, either before or after electrochemical treatment. Auger analysis confirmed that the percentage of $\mathrm{Cr}$ in the $\mathrm{Fe}-26 \mathrm{Cr}$ metallic layer was as expected, and that after electrochemical treatment, a significant quantity of $\mathrm{Fe}-\mathrm{Cr}$ metal remained, even for a $4 \mathrm{~nm}$ $\mathrm{Fe}-26 \mathrm{Cr}$ layer.

Cyclic voltammetry of slightly thicker sputtered layer samples was compared to that of the bulk material to ensure that the two electrodes behaved in a similar manner. A cyclic voltammogram on the $T a$ layer alone showed no peaks in the region of interest; thus the Tia acts as an essentially electrochemically inert substrate which is, however, required to maintain good electrical conductivity. Despite the significant $\mathrm{C}$ contamination of the 
Fe-26Cr layer, the cyclic voltammetric characteristics (at $0.5 \mathrm{mV} \mathrm{s}^{-1}$ ) of the thin layers were remarkably similar to those of the bulk Fe-26Cr alloy, as shown in Fig. 1. The second sweep on the thin film electrode shows all of the features of the sweep on the bulk material, namely an "active" peak at $-1.11 \mathrm{~V}$, a transpassiye peak at about $0.27 \mathrm{~V}$, oxygen evolution beginning at $-0.61 \mathrm{~V}$; during the subsequent cathodic scan the features observed consisted of a cathodic peak at $-0.27 \mathrm{~V}$ (corresponding to reduction of a higher oxide formed in the transpassive peak), a peak at $-0.85 \mathrm{~V}$ resulting in reduction of the Fe-contrining oxide, and finally hydrogen evolution beginning at $-1.36 \mathrm{~V}$. These peaks have previously been discussed in more detail (5). The first sweep, while exhibiting most of the expected characteristics, has a broadened and suppressed transpassive peak, and it seems likely that the first scan acts to "activate" the electrode surface. While the nature of the processes which occur in the first cycle are unknown, surface analysis revealed that they do not result in a reduction of the C contamination, nor any other detectable changes except in the $\mathrm{Cr}$ content of the oxide layer. It should be noted that an anodic activation of the sample was necessary to yield reproducible XANES spectra.

For reference, a series of XANES spectra of Cr standards are shown in Fig. 2. In general, the absorption edge moves to higher energy as the oxidation state of the $\mathrm{Cr}$ increases from zero to 6. Cr metal shows a plateau at about $5993 \mathrm{eV}$, while $\mathrm{Cr}(\mathrm{VI})$ has a very sharp and distinct peak at the same energy. This characteristic peak can be used to unequivocally establish the presence of $\mathrm{Cr}(\mathrm{VT})$ in a sample $(6,7)$. The peak arises from $\mathrm{Cr}$ in a tetrahedral geometry (9). Since the passive film on $\mathrm{Fe}-26 \mathrm{Cr}$ is expected to consist of mixed $\mathrm{Fe}$ and $\mathrm{Cr}$ oxides and hydroxides, the presence of this peak is a fingerprint for Cr(VI).

A series of XANES spectra on the thin layer electrodes under electrochemical control are shown in Fig. 3. The sample consisted of $4 \mathrm{~nm} \mathrm{Fe}-26 \mathrm{Cr}$ on $10 \mathrm{~nm}$ of Ta sputtered on Mylar. While a thinner Fe-26Cr layer would result in an increase in the signal from the passive film relative to that from the Fe-26Cr metal, a thicker $\mathrm{Fe}-26 \mathrm{Cr}$ metallic layer ensures that the sample behaves as much as possible like the bulk material, which. would not be the case if all of the metal was oxidized. Prciiminary experiments showed that reproducible XANES spectra were only obtained after the sample had been activated by an anodic treatment, as suggested by the cyclic voltammograms. Thus, the sample was cathodically reduced at $-1.5 \mathrm{~V}$ for $5 \mathrm{~min}$., then activated at $0.8 \mathrm{~V}$ for $5 \mathrm{~min}$., and finally cathodically reduced again at $-1.5 \mathrm{~V}$ for another 5 min. An initial XANES spectrum, Fig. 3(a), was collected at the cathodic potential. It shows a plateau at $5993 \mathrm{eV}$, followed by a steeply increasing edge. Comparison with the standands (Fig. 2) suggests that the sample is composed of a mixture of $\mathrm{Cr}$ metal and $\mathrm{Cr}$ (TII). The sample was then passivated by stepping to various anodic potentials and holding for $10 \mathrm{~min}$. The XANES data collection (which required about 10 min. per spectrum) was started immediately after stepping the potential. There is no detectable change in the XANES spectra for the passivated (potentials $\leq 0.2 \mathrm{~V}$ ) compared to the reduced surfaces. However, at a potential of $0.4 \mathrm{~V}$ (well into the transpassive peak), two features of the spectra change; a peak, as opposed to a plateau, appears at $5993 \mathrm{eV}$, and the main edge has a lower slope than at lower potentials. Both of these changes indicate tl.tt some of the $\mathrm{Cr}$ (III) in the film has been converted to $\mathrm{Cr}(\mathrm{VI})$. Altho: igh the slope of the main edge is not a simple measure of the oxidation state of $\mathrm{Cr}$, consideration of the spectra of the standards ( $\mathrm{Fig} .2$ ) indicates that a decrease in the slope would occur on the oxidation of a portion of the $\mathrm{Cr}$ (III) to $\mathrm{Cr}(\mathrm{VI})$, both because of the shift of the edge to higher energy, and tecause of the lower maximum absorption of $\mathrm{Cr}(\mathrm{VI})$. These features remain unchanged as the potential is incteased to $0.5 \mathrm{~V}$, and then decreased to $0.1 \mathrm{~V}$. However, once the potential is decreased to $-0.1 \mathrm{~V}$ (at the beginning of 
the reduction peak), the peak at $5993 \mathrm{eV}$ begins to diminish in size, and the slope of the main edge begi"s to increase. At $-0.3 \mathrm{~V}$ (through the cathodic wave) all evidence for $\mathrm{Cr}(\mathrm{VI})$ has disappeared from the XANES spectrum.

Electrochemical production of $\mathrm{Cr}(\mathrm{VI})$ in the anodic film on $\mathrm{Fe}-26 \mathrm{Cr}$ is reversible, as shown by the spectra in Fig. 3(h) to (j). After the $\mathrm{Cr}(\mathrm{VI})$ has been reduced at $-0.3 \mathrm{~V}$, it can be reformed by an anodic treatment at $0.6 \mathrm{~V}$, and reduced again by a subsequent treatment at $-0.3 \mathrm{~V}$. From Fig. 3(h) it is apparent that there is still a significant amount of metallic $\mathrm{Cr}$ remaining in the sample after these electrochemical treatments. Overall, a decrease in the edge height with time can be see:l when spectra at similar potentials are compared. This indicates that there is some dissolution of the sample.

The insert shows a direct comparison between the average of spectra (e) and (i) (both at $0.6 \mathrm{~V}$ ) and the average of spectra $(\mathrm{h})$ and $(\mathrm{j})$ (both at $-0.3 \mathrm{~V}$ ). This comparison makes the pre-edge peak attributed to $\mathrm{Cr}(\mathrm{VI})$ more distinct. The spectra shown in Fig. 3 were the result of about 10 minutes of data collection. In other experiments, not shown, spectra were improved in signal to noise ratio by increasing the collection time, however, the collection time was minimized for the illustrated series of experiments to reduce the dissolution of the sample.

The results of Fig. 3 clearly indicate that the produstion of $\mathrm{Cr}(\mathrm{Vl})$ in the anodic film on $\mathrm{Fe}-26 \mathrm{Cr}$ is associated with the transpassive wave centered at $0.28 \mathrm{~V}$, and that $\mathrm{Cr}(\mathrm{VI})$ is reduced in the cathodic wave at $-0.27 \mathrm{~V}$. Only small amounts of $\mathrm{Cr}(\mathrm{VI})$ are present in the oxide; if all of the $\mathrm{Cr}$ in the sample had been converted to $\mathrm{Cr}(\mathrm{VI})$, then the peak at $5993 \mathrm{eV}$ would be expected to reach the height of the main edge (see Fig. 2). No attempt was made to quantify the $\mathrm{Cr}(\mathrm{VI})$ concentration for the following reascas. Firstly, the amorphous nature of the $\mathrm{Cr}$ (III) and $\mathrm{Cr}$ (VI) oxides in the passive film on $\mathrm{Fe}-\mathrm{Cr}$ alloys might lead to changes in the details of the XANES features, and secondly, contamination of the metallic substrate by $C$ could result in the presence of $\mathrm{Cr}_{3} \mathrm{C}_{2}$ spectra in addition to the expected spectra of $\operatorname{Cr}(0)$, which would complicate the fitting procedue.

Finally, the air stability of $\mathrm{Cr}(\mathrm{VI})$ in the anodic film was investigated. Fig. 4(a) shows a XANES spectrum of a sample which had been treated at $0.8 \mathrm{~V}$, yielding clear indications of $\mathrm{Cr}(\mathrm{VI}){ }^{*}$ The sample was then disconnected from the potentiositat, the solution drained from the cell, and the surface of the sample rinsed with water. XANES spectra were recorded after various times of exposure to the laboratory amosphere (Fig. 4 (b) to (d)). While the characteristic peak at $5993 \mathrm{eV}$ was still present after $1.5 \mathrm{nr}$. of ex situ exposure it had completely disappeared by $16.5 \mathrm{hr}$. Clearly, $\mathrm{Cr}(\mathrm{VI})$ is not indefinitely stable under these conditions. Compared with the previous procedure where the electrochemical characteristics of Cr(VI) disappeared after only $15 \mathrm{~min}$. of laborator: ambient exposure (5), it was difficult to thoroughly dry the sample in the present series of experiments. Thus, it appears that the kinetics of the $\mathrm{Cr}$ (VI) reduction may be dependent on the ambient humidity. This possibility is currently under investigation.

\footnotetext{
"It should be noted that this particular sample had undergone quite extensive electrochemical treatments, which, in general would be expected to result in a depletion of Fe from the sample. Thus, the effective $\mathrm{Cr}$ content of the alloy may be larger than $26 \%$, yielding a larger Cr(VI) signal at $5993 \mathrm{eV}$ than for the previously discussed sample, which had not been cycled as extensively.
} 


\section{CONCLUSIONS}

XANES has been used to establish the presence of Cr(VI) in the anodic oxide film on Fe-26Cr alloy. The production of $\mathrm{Cr}(\mathrm{VI})$ is associated with the transpassive wave in the cyclic voltammogram, and its reduction with a corresponding reduction wave. The formation and reduction of $\mathrm{Cr}(\mathrm{VI})$ was reversible and only small amounts of $\mathrm{Cr}(\mathrm{VI})$ were detected in the film. Cr(VI) in the anodic film is not indefinitely stable to air exposure and is completely absent after many hours of air exposure.

\section{ACKNOWLEDGEMENTS}

This work was carried out in part under the auspices of the US Department of Energy, Division of Materials Sciences, Office of Basic Energy Science under Contract No. DE-AC02-76CH00016. XANES measurements were carried out at the National Synchrotron Light Source Beamline X19A.

\section{REFERENCES}

1. Th. Heumann and W. Rösener, J. Chem. Soc., 59, 722 (1955).

2. C.R. Clayton and Y.C. Lu, J. Electrochem. Soc., 133, 2465 (1986).

3. G.P. Halada and C.R. Clayton, in "Applications of Surface Science Methods to Environmental/Materials Interactions", to be published by the Electrochemical Society.

4. N. Hara and K. Sugimoto, J. Electrochem. Soc., 126, 1328 (1979).

5. J.A. Bardwell, G. I. Sproule, D. F. Mitchell, B. MacDougall and M.J. Graharn, J. Chem. Soc. Farad. Trans., 87, 1011 (1991).

6. G.G. Long, J. Kruger and D. Tanaka, J. Electrochem. Soc. 134, 264 (1987).

7. A.J. Davenport, H.S. Isaacs, G.S. Frankel, A.G. Schrott, C.V. Jahnes and M.A. Russak, J. Electrochem. Soc., 138, 337 (1991).

8. M. Kerkar, J. Robinson, A.J. Forty, Farad. Discuss. Chem. Soc., 89, 31 (1990).

9. F.W. Kutzler, C.R. Natoli, D.K. Misemer, S. Doniach and K.O. Hodgson, J. Chem. Phys., 73, 3274 (1980).

\section{DISCLAIMER}

\footnotetext{
This report was prepared as an account of work sponsored by an agency of the United States Government. Neither the United States Government nor any agency thereof, nor any of their employees, makes any warranty, express or implied, or assumes any legal liability or responsibility for the accuracy, completeness, or usefulness of any information, apparatus, product, or process disclosed, or represents that its use would not infringe privately ov/ned rights. Reference herein to any specific commercial product, process, or service by trade name, trademark, manufacturer, or otherwise does not necessarily constitute or imply its endorsement, recommendaticn, or favoring by the United States Government or any agency thereof. The views and opinions of authors expressed herein do not necessarily state or reflect those of the United States Government of any agency theresf.
} 


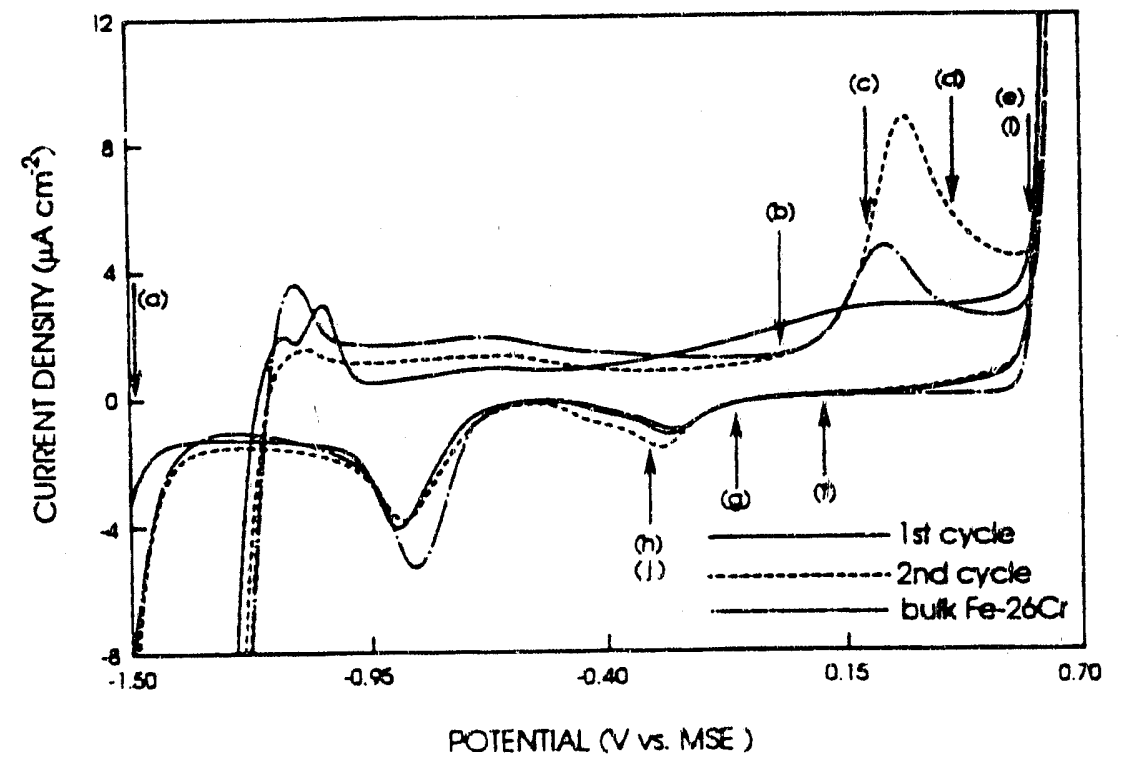

Fig. 1. Cyclic voltammograms $\left(0.5 \mathrm{mV} \mathrm{s}^{-1}\right)$ for $\mathrm{Fe}-26 \mathrm{Cr}$ bulk alloy and thin film electrodes. The thin film electrode consisted of $25 \mathrm{~nm}$ of Fe-26Cr on $25 \mathrm{~nm}$ of Ta sputtered onto Mylar. The bulk electrode was reduced as described previously (5), while the sweep was begun at $-1.44 \mathrm{~V}$ for the thin film electrode. The arrows refer to potentials at which the XANES spectra shown in Fig. 3 were collected.

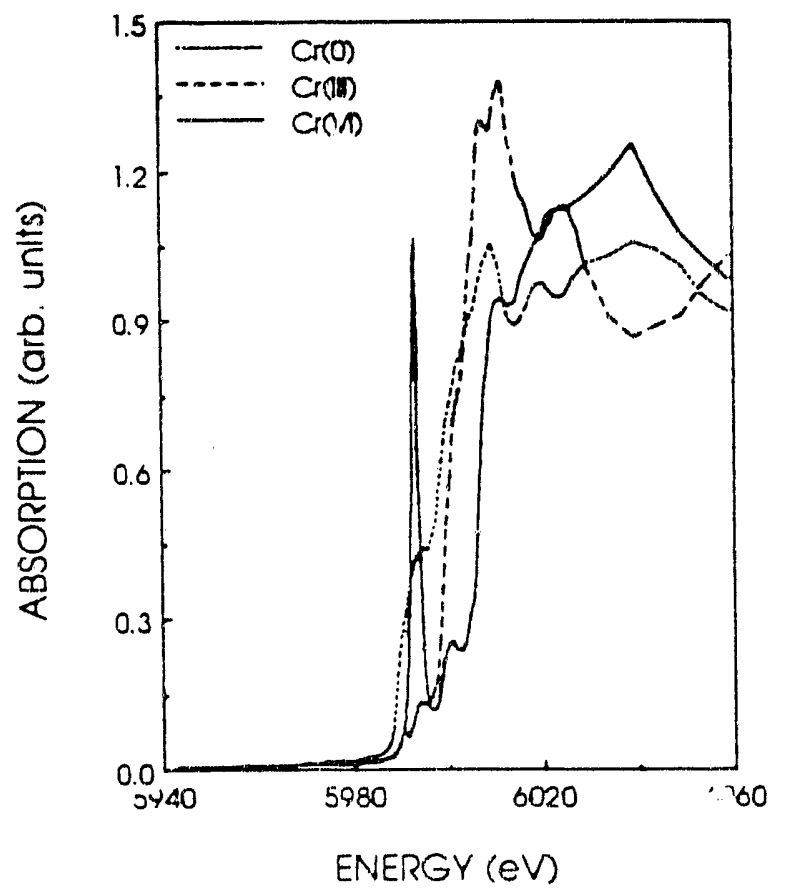

Fig. 2. XANES spectra of $\mathrm{Cr}$ foil $(\mathrm{Cr}(0))$, and $\mathrm{Cr}_{2} \mathrm{O}_{3}(\mathrm{Cr}(\mathrm{III}))$ and $\mathrm{K}_{2} \mathrm{CrO}_{4}(\mathrm{Cr}(\mathrm{VI}))$ powder standards. The spectra have been background subtracted and normalized at an energy of $6180 \mathrm{eV}$, where the EXAFS features are damped out. 


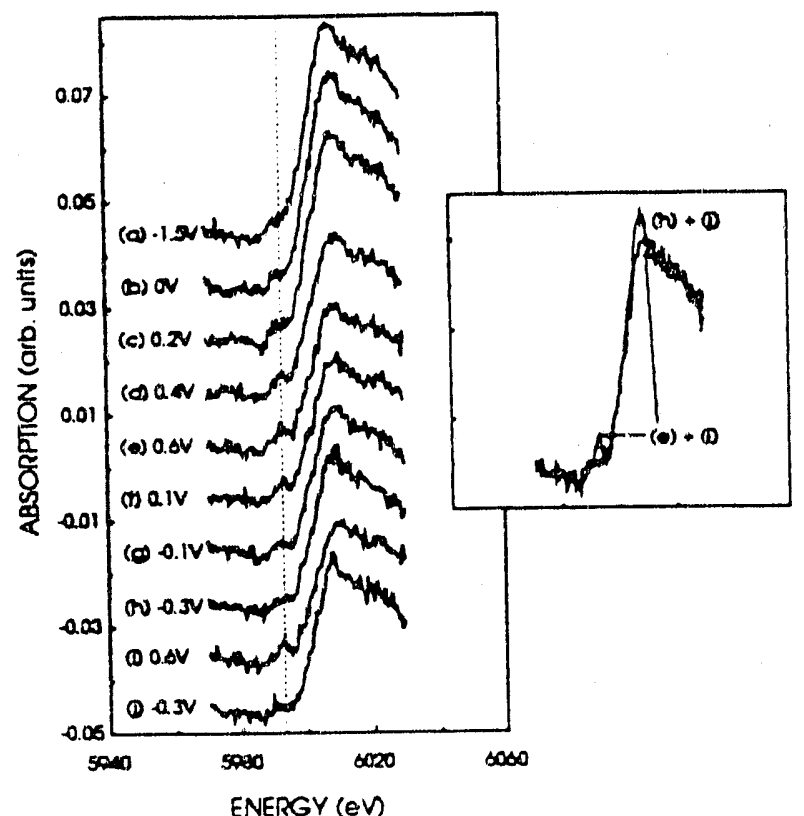

Fig. 3. In situ XANES spectra of a Fe-26Cr thin film electrode under potential control. The thin film electrode consisted of $4 \mathrm{~nm} \mathrm{Fe}-26 \mathrm{Cr}$ on $10 \mathrm{~nm}$ of Ta sputtered onto Mylar. The vertical dotted line indicates $5993 \mathrm{eV}$, which is the position of the pre-edge peak clearly associated with Cr(VI). The insert shows a direct comparison between the average of spectra (e) and (i) and the average of spectra $(h)$ and $(j)$.

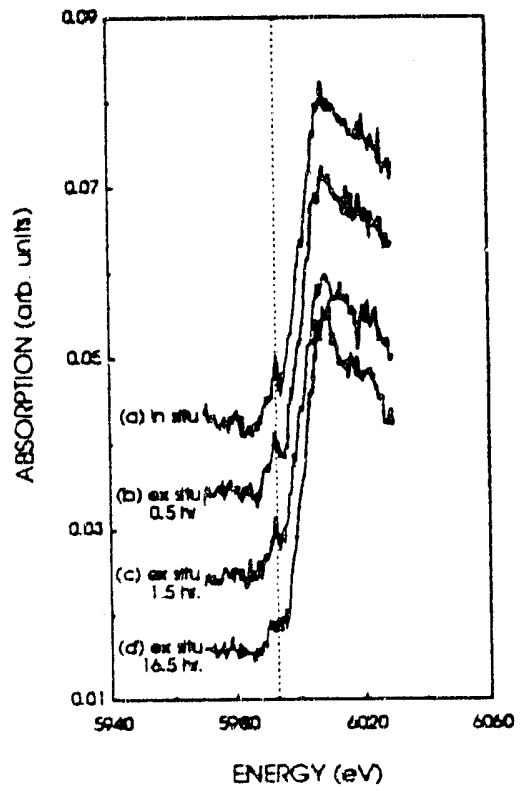

Fig. 4. In situ and ex situ XANES spectra of a thin film Fe-26Cr electrode consisting of $6 \mathrm{~nm}$ of Fe-26Cr on $20 \mathrm{~nm}$ of Ta sputtered onto Mylar. (a) in situ potentiostated at $0.8 \mathrm{~V}$, and ex situ (b) after $0.5 \mathrm{hr}$., (c) after $1.5 \mathrm{hr}$., and (d) after $16.5 \mathrm{hr}$. of air exposure. The vertical dotted line indicates $5993 \mathrm{eV}$, which is the position of the pre-edge peak clearly associated with $\mathrm{Cr}(\mathrm{VI})$. 

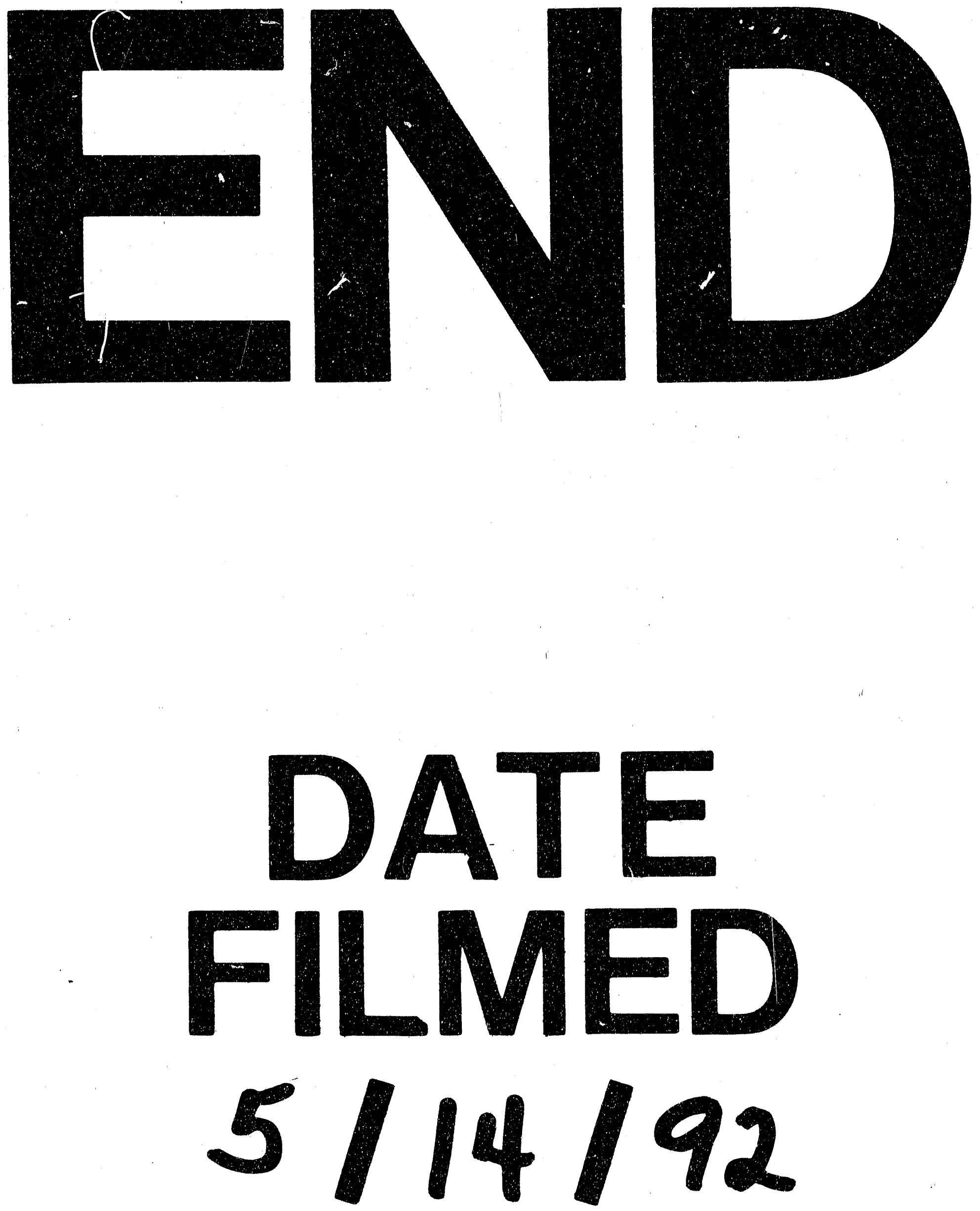
